Article

\title{
Improving the Downscaling of Diurnal Land Surface Temperatures Using the Annual Cycle Parameters as Disaggregation Kernels
}

\author{
Panagiotis Sismanidis ${ }^{1,2, *}$, Iphigenia Keramitsoglou ${ }^{1}$, Benjamin Bechtel ${ }^{3}$ and \\ Chris T. Kiranoudis ${ }^{1,2}$ \\ 1 Institute for Astronomy, Astrophysics, Space Applications and Remote Sensing, \\ National Observatory of Athens, Athens GR-15236, Greece; ik@noa.gr (I.K.); kyr@chemeng.ntua.gr (C.T.K.) \\ 2 School of Chemical Engineering, National Technical University of Athens, Athens GR-15780, Greece \\ 3 Center for Earth System Research and Sustainability, University of Hamburg, Hamburg DE-20146, Germany; \\ benjamin.bechtel@uni-hamburg.de \\ * Correspondence: panosis@noa.gr; Tel.: +30-210-810-9167
}

Academic Editors: Zhaoliang Li and Prasad S. Thenkabail

Received: 14 November 2016; Accepted: 28 December 2016; Published: 30 December 2016

\begin{abstract}
The downscaling of geostationary diurnal thermal data can ease the lack of land surface temperature (LST) datasets that combine high spatial and temporal resolution. However, the downscaling of diurnal LST data is more demanding than single scenes. This is because the spatiotemporal interrelationships of the original LST data have to be preserved and accurately reproduced by the downscaled LST (DLST) data. To that end, LST disaggregation kernels/predictors that provide information about the spatial distribution of LST during different times of a day can prove especially useful. Such LST predictors are the LST Annual Cycle Parameters (ACPs). In this work, multitemporal ACPs are employed for downscaling daytime and nighttime $\sim 4 \mathrm{~km}$ geostationary LST from SEVIRI (Spinning Enhanced Visible and Infrared Imager) down to $1 \mathrm{~km}$. The overall goal is to assess if the use of the ACPs can improve the estimation of the diurnal range of DLST (daytime DLST minus nighttime DLST). The evaluation is performed by comparing the DLST diurnal range maps with reference data from MODIS (Moderate Imaging Spectroradiometer) and also with data retrieved from a modified version of the TsHARP (Thermal Sharpening) algorithm. The results suggest that the ACPs increase the downscaling performance, improve the estimation of diurnal DLST range and produce more accurate spatial patterns.
\end{abstract}

Keywords: thermal remote sensing; land surface temperature; LST disaggregation; LST downscaling; diurnal temperature range; annual cycle parameters; SEVIRI; MODIS

\section{Introduction}

The remotely sensed land surface temperature (LST) is the directional radiometric temperature of the ensemble of surfaces viewed by a thermal infrared (TIR) sensor during the image acquisition process $[1,2]$. This physical highly dynamic parameter is a key quantity for the surface energy balance and a key input to many applications, such as the study of the urban thermal environment and the hydrological cycle [3,4]. Presently, LST data are primarily obtained (after the correction of the atmospheric and emissivity effects [1]) as a level-2 derivative of TIR satellite remote sensing [5]. However, due to technical and physical constrains, the available TIR satellite sensors cannot offer LST data that match the characteristic scale [6] of the LST diurnal cycle. This is due to the anti-correlation between the spatial and temporal resolution of a satellite sensor that prohibits the frequent acquisition $(<1-2 \mathrm{~h})$ of fine-scale $(0.1-0.2 \mathrm{~km}$ [7]) TIR data [8]. This issue hampers the exploitability of satellite LST datasets and to address it many research efforts have focused on the statistical downscaling 
(also referred as thermal sharpening) of coarse scale, but frequently acquired, TIR data [7-10], e.g., geostationary TIR data.

The statistical downscaling of thermal satellite data is an effective technique for enhancing the spatial resolution of thermal imagery using spatially distributed, statistically correlated auxiliary data (usually referred to as predictors, disaggregation kernels, or scaling factors) [11,12]. According to Zhan et al. [12], the core of the downscaling of thermal images can be understood as some inferential statistics that estimate the emitted spectral characteristic of surface targets with the use of features from the finer-scale disaggregation kernels [12]. This scaling process can be performed on digital numbers (DN), TIR radiances or LST (this work focuses on LST and thus the terms LST downscaling and LST predictors will be used henceforth); it fundamentally relates to three primary laws [13]: the Bayesian theorem, Tobler's first law of geography [14], and the surface energy balance equation; and it is based on four interrelated assumptions [11,12]. These assumptions are: (i) the assumption of additivity, i.e., that the energy flux interactions among components/pixels can be neglected; (ii) the assumption of separability, i.e., that the component values are statistically separable; (iii) the assumption of connectivity, i.e., that the DN/radiances/LST can be predicted from other ancillary data (i.e., the LST predictors); and (iv) the assumption of convertibility, i.e., that the conversion of spatial/spectral/temporal/angular information to another kind is possible.

In general, the workflow of a LST statistical downscaling scheme consists of three major operations [15]. The first operation is the upscaling and co-registration of the fine-scale LST predictors to the coarse scale LST data. The second operation is the generation of a statistical model on the basis of the coarse-scale LST data and predictors; and finally, the last operation is the application of this model to the fine-scale LST predictors so as to generate the downscaled LST (DLST) data. The employed empirical model can be linear or nonlinear $[12,13]$ depending mostly on the type and number of LST predictors employed (for downscaling TIR DN or radiances, the nonlinear factors of the atmospheric and emissivity effects should also be taken into consideration during this selection [12]). Zhan et al. [11] discuss that simple tools such as linear and quadratic tools are effective when the predictors' number is low (e.g., $[9,10,16,17])$, while complex tools such as support vector regression machines (SVM) are better suited when multiple LST predictors are employed (e.g., [18-20]). In principle, the LST is determined by numerous factors, including topography, vegetation abundance and vigor, soil moisture, land cover and meteorological conditions [16]; and usually the relationship between the LST data and the LST predictors is nonlinear [13]. However, this nonlinearity is so complex $[12,16]$ that the derivation of explicit global models is not an easy task (a localization strategy can be carried out as in $[21,22]$ and a linear relationship can be individually constructed for each group of adjacent pixels) and hence even to this date no strong evidence, that support whether the linearity or nonlinearity performs better, exist [12].

Even more than the applied model, the set of LST predictors are a key element of every LST statistical downscaling scheme. This is because the LST predictors indicate the LST distribution in the fine spatial resolution and drive the empirical model [12]. The composition and selection of appropriate LST predictors should refer to the understood relations of LST to other biophysical variables (e.g., vegetation cover, land surface albedo, topography and soil moisture status) [20], which is a key for meeting the connectivity assumption [11]. The choice of LST predictors should also consider: (i) the spatial scale, since the suitability of the kernel is partly determined by this factor (a key assumption for statistical downscaling studies is that the relationship between the LST data and the predictors is scale invariant $[15,23]$ ); (ii) the local particularities of the study area; and (iii) the temporal cycle (diurnal or annual) $[11,15]$ because it might render some LST predictors less effective or even ineffective (e.g., the correlation between the Normalized Difference Vegetation Index (NDVI), which is a widely used LST predictor, and LST is not persistent in time due to seasonal variations in the vegetation cover $[24,25])$.

In recent literature several LST downscaling methods have been proposed utilizing various LST predictors-either individually or by combining them into larger sets—such as vegetation indices 
(VIs), topography data, impervious maps and visible/near-infrared (VNIR, 0.4-1.4 $\mu \mathrm{m}$ ) or TIR images. For instance, Kustas et al. [9] utilized the NDVI with a quadratic regression tool (this method is referred in literature as disTrad: disaggregation procedure for radiometric surface temperature), whereas Agam et al. [10] used the fractional vegetation cover with a linear tool and also other variants of disTrad. Inamdar et al. [16] employed the emissivity for downscaling GOES (Geostationary Environmental Satellite) LST data, while Essa et al. [26] expanded the disTrad methodology and tested 15 remote sensing based indices (individually) as LST predictors (including soil, vegetation and built-up indices). Stathopoulou and Cartalis [8] enhanced the spatial resolution of AVHHR (Advanced Very High Resolution Radiometer) LST data using as LST predictors the effective emissivity and a LST map retrieved from Landsat 5 data.

Downscaling methods that utilize large sets of LST predictors became available after 2009 as the study of Zhan et al. [11] reveals. To that end, Zakšek and Oštir [21] used a LST predictor set comprising VIs, albedo, emissivity, land cover, slope, aspect, and the sky view factor data to downscale LST images retrieved from SEVIRI (Spinning Enhanced Visible and Infrared Imager), while Keramitsoglou et al. [19] employed a set of 17 LST predictors that included topography data, land cover data, VIs and emissivity data in conjunction with a SVM tool. Merlin et al. [27] used the fractional photosynthetically active and non-photosynthetically active vegetation cover for downscaling MODIS (Moderate Resolution Imaging Spectroradiometer) thermal data, while Weng et al. [18] utilized VIs, albedo, emissivity and elevation data to downscale GOES LST data. Lastly, Hutengs and Vohland [20] used as LST predictors VNIR and SWIR (Shortwave Infrared Radiation, 1.4-3 $\mu \mathrm{m}$ ) surface reflectance data, elevation data and derivatives (i.e., the solar incidence angle and the sky view factor), and a land cover map with a random forest regression tool.

It is clear from the above that the most widely used LST predictors are VNIR-based (e.g., the NDVI) or static (e.g., the altitude) and that little attention has been given into TIR-based LST predictors. However, TIR-based LST predictors can prove quite useful for downscaling diurnal LST data. This is because being derived from satellite thermal data they incorporate the location-specific seasonal thermal response as well as the thermal surface properties and thus perform more consistently over various land cover types and landscapes. In addition, TIR-based LST predictors can also provide information about how these patterns change with time. This is possible when TIR multitemporal LST predictors are employed, i.e., LST predictors that indicate the LST spatial distribution during different times of a day (e.g., morning, noon, afternoon, night) or seasons. The Annual Cycle Parameters (ACPs) [28] are such multitemporal LST predictors. This data product, which is globally available and derived from multitemporal thermal satellite data, presents a continuous description of the thermal surface behavior and the thermal surface characteristics (i.e., the "thermal landscape") using a set of five parameters [28,29]. These five parameters are: the mean annual surface temperature (MAST); the yearly amplitude of surface temperature (YAST); the phase shift of the sine function that approximates the LST annual cycle (Theta; it is estimated relative to the spring equinox); the number of clear-sky observations used for the fit (NCSA); and lastly the root-mean-square-error (RMSE) of the sine fit, which is a measure for the inter-diurnal and inter-annual LST variation. The estimation of these five predictors corresponds to the acquisition time of the satellite LST data. Thus for multiple acquisitions within a day, multiple sets of ACPs can be generated, i.e., ACPs that refer to morning, noon, afternoon or night hours. Some studies have used the ACPs for downscaling LST data [7,15,30,31]. However, the use of this dataset for downscaling diurnal LST data and its ability to provide information about the LST diurnal fluctuations has not been studied in great depth, mainly because it is a very recent data product.

This study investigates the use of the MAST, YAST and Theta as LST predictors for downscaling daytime and nighttime geostationary LST data. In particular, it focuses on the LST change between 10:30 and 22:30 UTC; and 13:30 and 01:30 UTC, and assesses the capacity of YAST, MAST and Theta to reproduce characteristics of the LST diurnal cycle in the downscaling process. Following this Introduction, in Section 2 the employed LST data and LST predictors are described, as well as the 
research objective of this work and the performed experiment. In Sections 3 and 4, the results obtained are presented and discussed, respectively, while, in Section 5, the drawn conclusions are outlined.

\section{Materials and Methods}

\subsection{Study Area}

The study area is Rome Greater Region in Italy. It extends $60 \mathrm{~km}$ around the City of Rome and covers an area of $10,350 \mathrm{~km}^{2}$ (Figure 1). The altitude of the study area varies from 0 to $1.5 \mathrm{~km}$. The prevailing land cover types are agricultural $(\sim 50 \%)$ and vegetated lands $(\sim 40 \%)$ which amount to $\sim 90 \%$ of the total area. The remaining $\sim 10 \%$ correspond to impervious surfaces. The key reason for selecting Rome Greater Region as the study area is its well-structured land cover layout. In particular, each land cover class is relatively homogeneous and confined to a certain location with easily-identifiable boundaries.

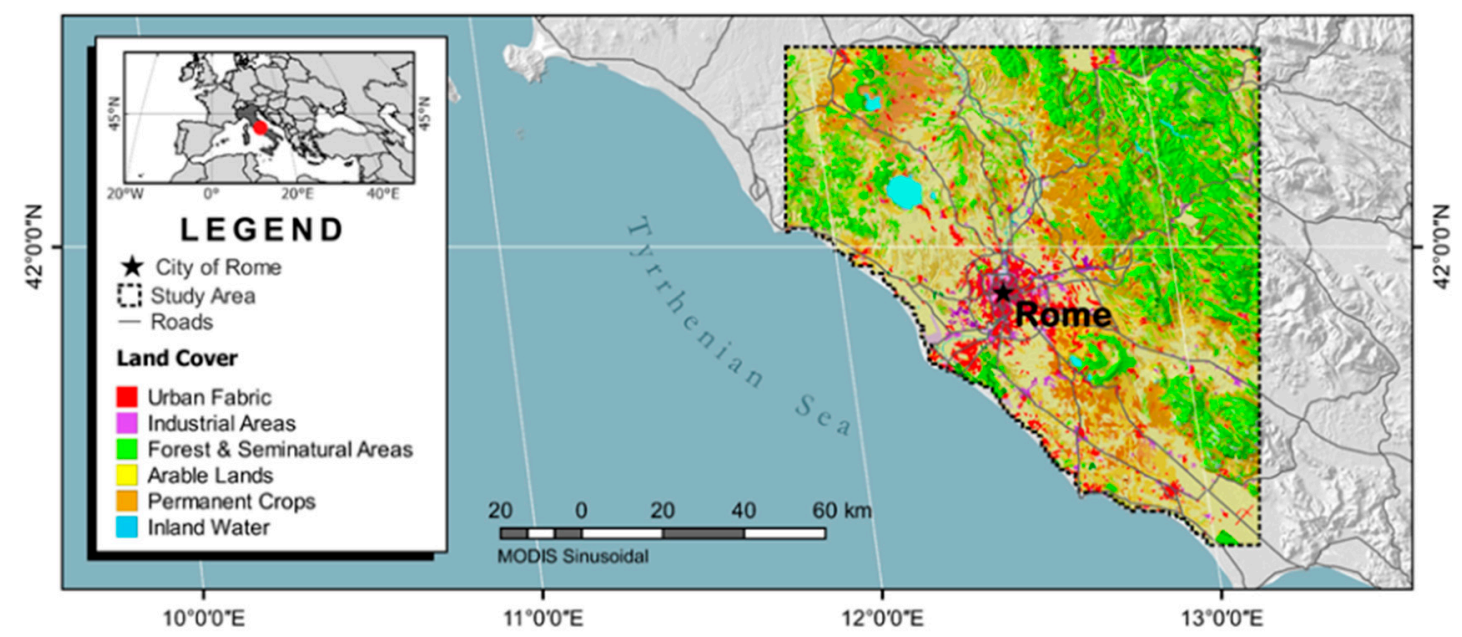

Figure 1. The study area.

\subsection{Data}

\subsubsection{Satellite LST Imagery}

The primary data employed in this study are LST images of Rome Greater Region (Figure 1) acquired during summer 2014 (Days-of-Year (DOYs): 152-243) by Terra and Aqua MODIS and Meteosat-10 SEVIRI instruments. In particular, the employed MODIS LST data are the daily $1 \mathrm{~km}$ version 5 MOD11A1 (from Terra satellite) and MYD11A1 (from Aqua satellite) data products [32]. These products are generated from MODIS TIR bands $31(10.78-11.28 \mu \mathrm{m})$ and $32(11.77-12.27 \mu \mathrm{m})$ using a generalized split-window algorithm [1] and have an accuracy of $1-2{ }^{\circ} \mathrm{C}$ [33]. Each MOD11A1/MYD11A1 data file includes two LST images one corresponding to the daytime acquisition (for Terra at 10:30 UTC and for Aqua at 13:30 UTC) and one to the nighttime (for Terra at $~ 22: 30$ UTC and for Aqua at 01:30 UTC). Further, information about the viewing time, the viewing zenith angle (VZA) and the land surface emissivity are also delivered.

In addition to the above, SEVIRI LST data concurrent to the acquisition times of the MOD11A1 and MYD11A1 data products, are also employed (the time deviation between the corresponding MODIS and SEVIRI data is less than $7.5 \mathrm{~min}$ which is not considered a problem). These data have a coarser spatial resolution of $4 \times 5 \mathrm{~km}^{2}$ and were retrieved from the EUMETcast data acquisition station that the Institute for Astronomy, Astrophysics, Space Applications and Remote Sensing of the National Observatory of Athens (IAASARS/NOA) operates. The IAASARS/NOA system uses an in-house SVM-based LST retrieval algorithm [34,35] that utilizes as input the cloud-free TIR radiances from the 10.8 and $12 \mu \mathrm{m}$ SEVIRI spectral bands and emissivity information from the MOD11A2 data 
product [33]. The evaluation of the employed SEVIRI LST data was performed in [35] using concurrent and collocated, high quality (accuracy of 1-2 ${ }^{\circ} \mathrm{C}$ ) independent Meteosat-10 SEVIRI data from LandSAF (Land Surface Analysis Satellite Application Facility [36]) and showed a mean difference of $-0.19{ }^{\circ} \mathrm{C}$, a RMSE of $0.5^{\circ} \mathrm{C}$ and a Pearson's correlation coefficient (Rho) of $99.8 \%$.

\subsubsection{LST Predictors}

The LST predictors employed in this study (Table 1) are: altitude data from the Shuttle Radar Topography Mission digital elevation model (SRTM DEM) [37]; NDVI data from the MODIS MOD13A2 version 5 data product [38]; $12 \mu \mathrm{m}$ emissivity $\left(\varepsilon_{12 \mu \mathrm{m}}\right)$ data from the MODIS MOD11A2 version 5 data product [32]; visible $(0.3-0.7 \mu \mathrm{m})$ white-sky albedo (WSA) data from the MODIS MCD43B3 version 5 data product [39]; and LST annual climatology data in the form of the ACPs [28] (Figure 2). The selection of the LST predictors is based on the findings of $[7,19-21,40,41]$.

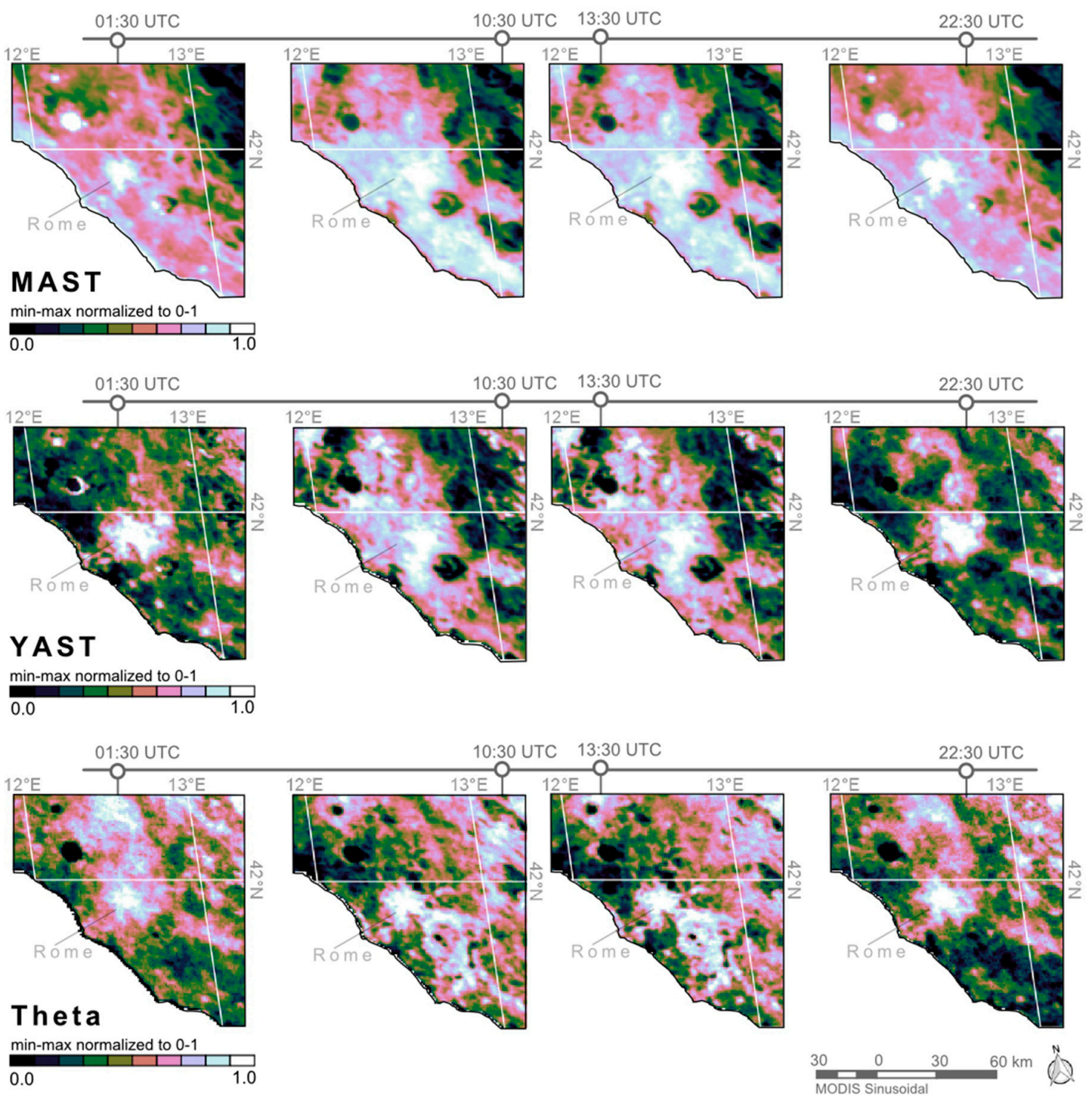

Figure 2. The 01:30, 10:30, 13:30 and 22:30 UTC Mean Annual Surface Temperature (MAST), Yearly Amplitude of Surface Temperature (YAST) and Theta Annual Cycle Parameters (ACPs) for the study area.

The SRTM DEM is a near-global, high quality DEM available free-of-charge at a spatial resolution of 30 and $90 \mathrm{~m}$. The absolute geolocation and height errors of SRTM DEM for the Eurasia continental 
landmass are 8.8 and $6.2 \mathrm{~m}$, respectively [42]. For use in this study the $90 \mathrm{~m}$ SRTM DEM of Rome Greater Region was upscaled to $1 \mathrm{~km}$ using a bilinear convolution and reprojected to the MODIS sinusoidal map projection. The MOD13A2 [38] is a global $1 \mathrm{~km}$ vegetation index product that is generated every 16 days. The MOD11A2 [32] and MCD43B3 [39] are also $1 \mathrm{~km}$ globally available 16-day data products. The emissivity data of the MOD11A2 are estimated using the land cover-based classification method presented in [43], while the WSA data (bihemispherical reflectance) of the MCD43B3 by integrating each pixel's BRDF (Bidirectional Reflection Distribution Function) over all viewing and irradiance directions. Lastly, the LST annual climatology data employed in this work are the 01:30, 10:30, 13:30 and 22:30 UTC 1 km MAST, YAST and Theta ACP components (Figure 2) retrieved using the method presented in [28] from a five-year (2009-2013) time series of MODIS LST data.

Table 1. The LST data and LST predictors employed in this study.

\begin{tabular}{ccccc}
\hline Data & Accuracy & Spatial Resolution & Map Projection & Source \\
\hline MOD11A1/MYD11A1 & $1-2{ }^{\circ} \mathrm{C}$ & $1 \times 1 \mathrm{~km}^{2}$ & MODIS Sinusoidal & NASA's EOSDIS $^{1}$ \\
SEVIRI LST & $1-2{ }^{\circ} \mathrm{C}$ & $4 \times 5 \mathrm{~km}^{2}$ & GEOS & IAASARS/NOA $^{2}$ \\
SRTM DEM & $6.2 \mathrm{~m}$ & $1 \times 1 \mathrm{~km}^{2}$ & MODIS Sinusoidal & USGS $^{2}$ \\
MOD13A2 (NDVI) & \pm 0.025 & $1 \times 1 \mathrm{~km}^{2}$ & MODIS Sinusoidal & NASA's EOSDIS $^{1}$ \\
MOD11A2 $(\varepsilon 12 \mu \mathrm{m})$ & $1.9 \%[44]$ & $1 \times 1 \mathrm{~km}^{2}$ & MODIS Sinusoidal & NASA's EOSDIS $^{1}$ \\
MCD43B3 $($ WSA) & $<5 \%$ & $1 \times 1 \mathrm{~km}^{2}$ & MODIS Sinusoidal & NASA's EOSDIS $^{1}$ \\
ACPs & - & $1 \times 1 \mathrm{~km}^{2}$ & MODIS Sinusoidal & UHH CliSAP $^{3}$ \\
\hline
\end{tabular}

${ }^{1}$ NASA's Earth Observing System Data and Information System (EOSDIS); ${ }^{2}$ United States Geological Survey Earth Explorer website; ${ }^{3}$ University of Hamburg Integrated Climate Data Center.

\subsection{Method}

\subsubsection{Research Objective and Experimental Setup}

This study investigates if the use of the multitemporal LST predictors MAST, YAST and Theta can increase the performance of LST downscaling and in particular if these LST predictors can improve the estimation of the DLST diurnal range, i.e., the DLST difference between daytime and nighttime data. In this work, the term diurnal range is not used explicitly since the employed satellite data are not the daily maximum and minimum temperatures, which are normally used for the estimation of the diurnal temperature range. The study of the DLST diurnal range is a strong indicator of how well the downscaling process can reproduce the diurnal LST cycle (and the impact of short-term weather and seasonal effects) and preserve the spatiotemporal interrelationships of temporally dense LST data. This is a critical issue in the downscaling of geostationary LST data as discussed in [15] because it can affect the exploitability of the generated DLST data. Hence, in order to answer the aforementioned research question, the experiment presented in Figure 3 was devised and performed.

The basic concept of this experiment is to estimate two $1 \mathrm{~km}$ SEVIRI DLST diurnal range maps (daytime DLST minus nighttime DLST) using two different sets of LST predictors-the first comprising VNIR-based and static LST predictors (Scheme 1; control data) and the second VNIR-based, static and multitemporal LST predictors (Scheme 2) -and then to compare them with a reference $1 \mathrm{~km}$ LST diurnal range map retrieved from MODIS data. The overall goal is to assess the changes induced by the TIR multitemporal LST predictors on the DLST data. In this study the employed VNIR-based and static LST predictors are the NDVI, the SRTM altitude, the $\varepsilon_{12 \mu \mathrm{m}}$, and the WSA, while the TIR multitemporal are the MAST, YAST and Theta. The reference data originate from MOD11A1 and MYD11A1 LST data products, while the employed downscaling method is based on a multiple linear regression (discussed in detail in Section 2.3.2). 


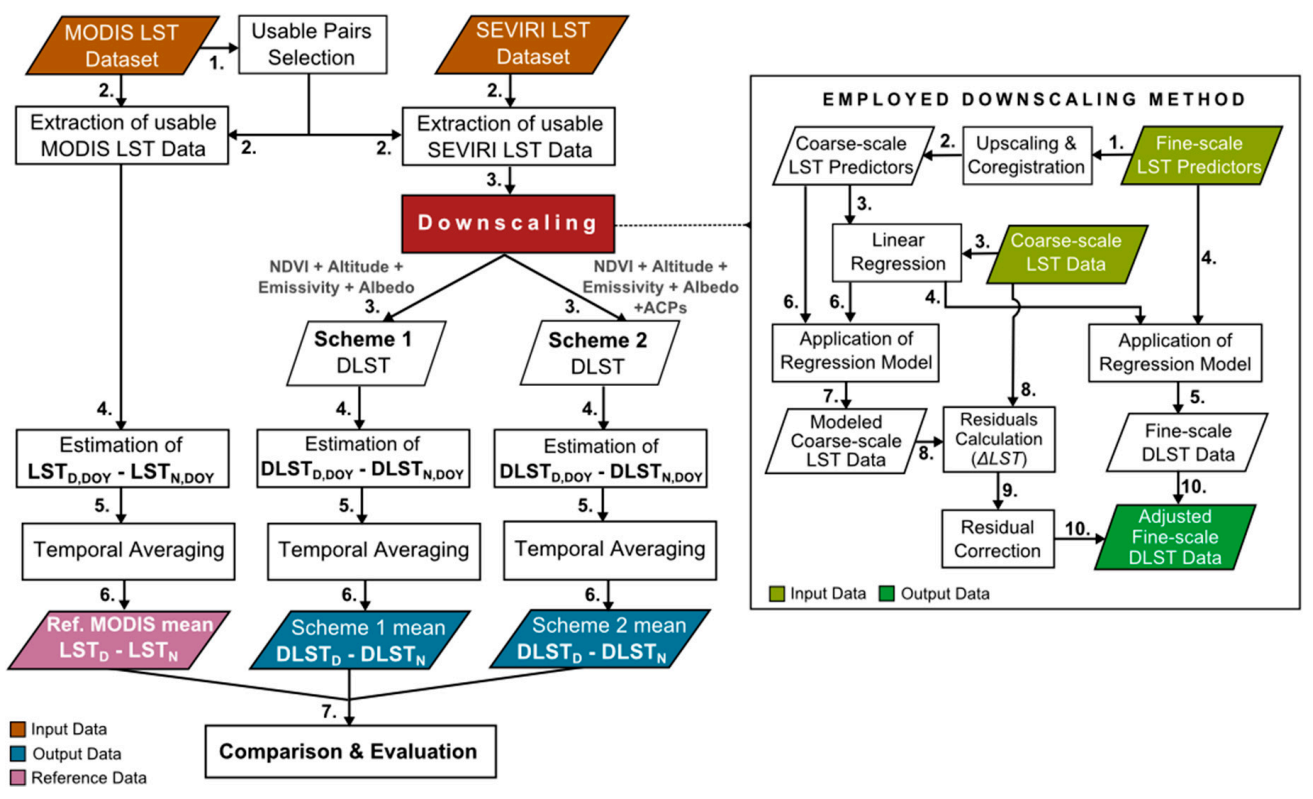

Figure 3. The experimental setup of this study.

Scheme 1, which is the control of this study's experiment, is in essence a modified version of the TsHARP (thermal sharpening) algorithm [10] that is widely used as a reference in the downscaling literature $[20,22,41,45]$. This LST downscaling algorithm exploits the strong correlation of NDVI with LST and uses linear regression to model it. The advantage of using a linear equation in contrast to other approaches (e.g., a polynomial function) is that it is less sensitive to the outliers of the upper and lower tails of the NDVI distribution [10]. However, the use of TsHARP in this study may prove precarious. This is because the correlation between NDVI and LST weakens during the night [24] and that can compromise the performance of TsHARP for downscaling nighttime LST data. Hence, to prevent this issue, altitude, $\varepsilon_{12 \mu \mathrm{m}}$, and WSA are also added as LST predictors. Altitude in particular is known to explain substantial nighttime LST variation [40].

The experimental setup adopted in this study (Figure 3) consists of four major stages. The first stage is the selection of the cloud-free scenes that will be used for the estimation of the diurnal range maps. The second stage is the downscaling of the previously selected coarse-scale SEVIRI LST data. The third stage is the estimation of the $1 \mathrm{~km}$ daily DLST and reference LST diurnal range maps (daytime minus nighttime), and the last stage is the comparison and evaluation of the results obtained. Specifically, the DLST diurnal range maps employed in the evaluation are estimated using Equation (1) and are the average of the daily DLST diurnal range maps estimated in stage three. In this equation, $n$ is the number of days used, while $D L S T_{D, i}$ and $D L S T_{N, i}$ are the daytime and nighttime $1 \mathrm{~km}$ SEVIRI DLST for DOY $i$, respectively. Equation (1) is also used for the estimation of the reference MODIS diurnal range maps using as input the corresponding $1 \mathrm{~km}$ daytime and nighttime MODIS LST data.

$$
\text { mean diurnal DLST range }=\frac{1}{n} \sum_{i=1}^{n}\left(D L S T_{D, i}-D L S T_{N, i}\right)
$$

The experiment presented above is performed twice. The first time studying the mean diurnal range maps between 10:30 and 22:30 UTC (i.e., the Terra MODIS daytime and nighttime acquisition times) and the second time between 13:30 and 01:30 UTC (i.e., the Aqua MODIS daytime and nighttime acquisition times). For the first experiment, which is referred in the text as 10:30 vs. 22:30 UTC analysis, the reference data are retrieved from the employed MOD11A1 data and for the second (referred in the text as 13:30 vs. 01:30 UTC analysis) from the MYD11A1 data.

As with most TIR remote sensing studies an important issue that can influence the analysis of the LST data is the impact of short-term weather effect [46]. Short-term weather effects influence 
the LST and especially the LST spatial patterns, e.g., a rainfall event can significantly change the emissivity of a region. For this reason it is advisable to use time series of LST data instead of individual scenes $[15,46]$. This way the results will be more representative for the study area. Hence, to make this study insusceptible to short-term weather effects, summer 2014 (DOYs: 152-243) was selected as the study period. The selection of this study period is based on the following four reasons: (i) it can provide a representative dataset for the purpose of this study; (ii) using LST data from the same year will ensure that the impact of phenological changes on the LST patterns will be reduced; (iii) the negative correlation of LST and NDVI, which is vital for the successful downscaling of LST data, is stronger during summer months [24]; and (iv) using summer data will ensure the availability of the most cloud-free daytime and nighttime LST data. This is especially important since for the estimation of the diurnal range maps cloud-free conditions during daytime and nighttime are required. In this work only LST and DLST diurnal range maps with low cloud cover (CC) are employed. In particular 33 scenes are employed for the 10:30 vs. 22:30 UTC analysis (median CC =12\%) and 28 for the 13:30 vs. 01:30 UTC analysis (median CC $=19 \%$ ). The DOYs of the selected scenes are presented in Table 2. For consistency reasons, the same DOYs are used for the calculation of the SEVIRI DLST and MODIS LST (i.e., the reference data) diurnal range maps. The temporal averaging of the DLST diurnal range data using Equation (1) is justified on the basis that the MODIS data acquisition time is not exactly the same for each satellite overpass and that would complicate the explanation and the discussion of the results. Hence, following this approach, even though it adds an additional source of statistical noise, makes the performed analysis more straightforward.

Table 2. The selected days-of-year (DOYs).

\begin{tabular}{cl}
\hline Analysis & \multicolumn{1}{c}{ DOYs (Year: 2014) } \\
\hline \multirow{2}{*}{ 10:30 vs. 22:30 UTC } & $153,159,160,161,162,173,175,182,184,185,187,189,192,196,198,199,208$, \\
& $212,216,217,219,221,223,225,226,230,232,233,235,237,240,241,242$ \\
\hline \multirow{2}{*}{ 13:30 vs. 01:30 UTC } & $155,160,171,180,181,183,185,186,188,192,196,197,199,201,206,208,212$, \\
& $213,217,218,219,220,222,226,229,231,234,242$ \\
\hline
\end{tabular}

Another important issue that can influence the analysis of LST data is thermal anisotropy [47,48]. Thermal anisotropy refers to the angular variation of TIR radiation. This effect is stronger during daytime and can make the LST of the same target to vary more than $2-4{ }^{\circ} \mathrm{C}$ when viewed by different directions [47,48]. Thermal anisotropy is known to influence the comparison of LST data $[1,48,49]$ and for this reason it is important to adopt compensation strategies when comparing LST data from different sources, as is this case. To that end, thermal anisotropy effects are more difficult to handle for MODIS than SEVIRI. This is because the MODIS VZA can range from $-55^{\circ}$ to $+55^{\circ}$ (the " + " sign means the sensor view the area from west, while the "-" from the east [49]), while SEVIRI, being onboard a geostationary satellite, acquires data with a constant VZA and azimuth angle (equal to $+50^{\circ}$ and $+18.4^{\circ}$, respectively, for the study area). Even though this issue has attracted considerable attention in recent years, no mature compensation methods are available yet. Nevertheless, a good practice for controlling this problem is to utilize LST data acquired with a similar viewing geometry (ideally it should be the same) [1,15]. This study follows this approach. In particular, the performed analysis is based on the assumption that it is possible to compare and average LST diurnal range maps from different dates, provided that they are estimated from daytime and nighttime LST data (of the same DOY) with highly similar VZAs. In particular, it is assumed that by subtracting the two LST images (i.e., the daytime minus nighttime) the primary signal remaining is of the actual LST diurnal change. Following this approach, it is possible to exploit the fact that the VZAs of daytime and nighttime MODIS data from the same DOY are very similar, as presented in Figure 4. In this figure the VZAs of the MODIS LST data employed in this work (Table 2) are presented. In particular, the daytime-nighttime MODIS VZA differences for the selected scenes range between $6.5^{\circ}$ and $10^{\circ}$ with a median of $8^{\circ}$. 

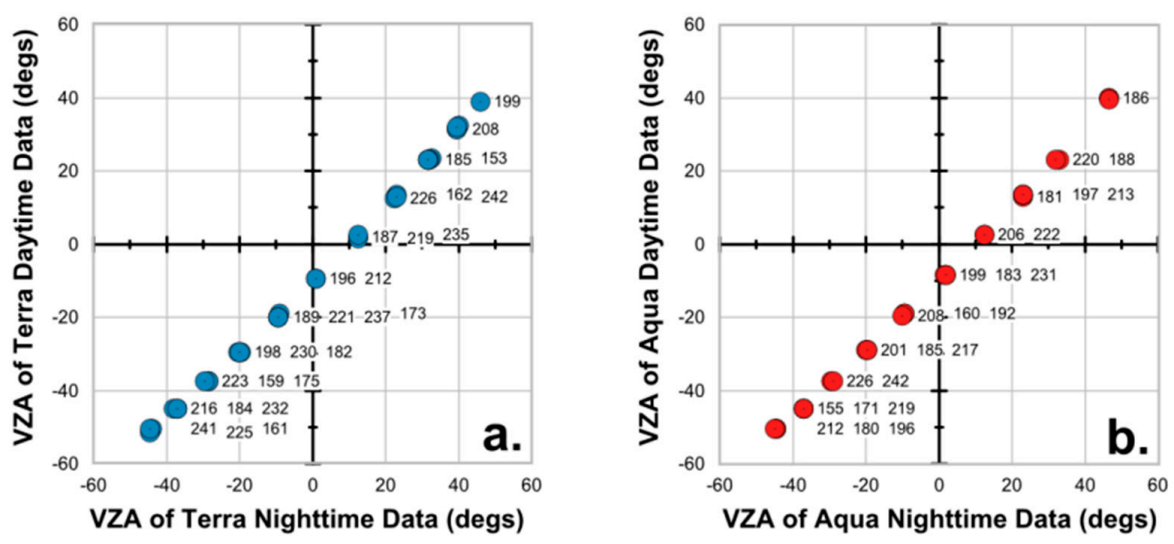

Figure 4. The VZA of the employed daytime and nighttime LST data retrieved from: (a) Terra MODIS; and (b) Aqua MODIS. The corresponding DOY values are also presented.

\subsubsection{Employed LST Downscaling Method}

The LST downscaling method employed in this work is based on TsHARP [10] and utilizes a multiple linear regression. This type of regression attempts to model the relationship between the LST predictors (i.e., the explanatory variables) and the LST data (i.e., the response variable) by fitting a linear equation to the observations. The general form of a multiple linear regression is presented in Equation (2). In this equation, $y$ is the response variable; $k$ is the number of explanatory variables used; $a_{0}, \ldots, a_{k}$ are the regression coefficients; and $x_{0}, \ldots, x_{k}$ are the explanatory variables. A key advantage of using a linear regression tool is its simplicity and efficiency [11].

$$
y=a_{0}+a_{1} \cdot x_{1}+a_{2} \cdot x_{2}+\cdots+a_{k} \cdot x_{k}
$$

The workflow of the LST downscaling method employed in this work is presented in Figure 3 and consists of three major operations. The first operation is the upscaling and co-registration of the fine-scale LST predictors to the coarse-scale LST data and the min-max normalization of the LST predictors between 0 and 1 so as to have comparable values (the normalization boundaries used are common between the $1 \mathrm{~km}$ and $4 \mathrm{~km}$ version of each LST predictor). The upscaling and co-registration process is performed using an intermediate $1 \times 1 \mathrm{~km}^{2}$ grid that assigns which $1 \mathrm{~km}$ pixels belong to each coarse scale $4 \times 5 \mathrm{~km}^{2}$ pixel on the basis of their geographical coordinates similar to [19] and [21]. The coarse-scale LST predictors are estimated eventually as the mean of all the fine scale pixels that belong to each coarse-scale cell. The second operation is the development of the regression model (Equation (2)) that describes the relationship between the coarse-scale LST data and LST predictors. The derived linear regression model is global and unique for each image employed. This selection is justified on the fact that the study area is of limited extent. The third operation of the employed method is the application of the retrieved regression model to the fine scale LST predictors to generate the DLST image data. The third operation is coupled with a DLST adjustment process (i.e., a residual correction) as in TsHARP [10] and also in $[9,20,41]$. This process aims to compensate the loss of variability due to the inflexibility of the linear regression tool and it is based on the difference of the observed and modeled coarse-scale LST data (Figure 3). In particular, the residuals ( $\triangle L S T$ ) between the modeled $\left(L S T_{c, \text { mod }}\right)$ and the observed coarse-scale LST ( $\left.L S T_{c, o b s}\right)$ are calculated using Equation (3) and then incorporated to the spatially enhanced LST data using Equation (4). Prior to the application of Equation (4), the $\Delta L S T$ are resampled to the $1 \times 1 \mathrm{~km}$ DLST grid. A smoothing filter is also applied to the resampled $\Delta L S T$ to prevent the occurrence of boxy effects on the DLST data, as suggested in [41]. The DLST adj are the primary output of the employed downscaling method and the main input to Equation (1). 


$$
\begin{gathered}
\Delta L S T=L S T_{c, o b s}-L S T_{c, m o d} . \\
D L S T_{a d j}=D L S T+\Delta L S T
\end{gathered}
$$

As discussed in the previous section, the downscaling method presented above is employed twice. The first time utilizing as LST predictors the NDVI, the altitude, the $\varepsilon_{12 \mu \mathrm{m}}$, and the WSA (Scheme 1; Equation (5)), and the second time all of the above, plus MAST, YAST and Theta (Scheme 2; Equation (6)). The overall goal is to use the DLST diurnal range map of Scheme 1 as control to assess the performance of MAST, YAST and Theta as LST predictors.

$$
\begin{gathered}
\text { DLST }=a_{0}+a_{1} \cdot N D V I+a_{2} \cdot \text { Altitude }+a_{3} \cdot \varepsilon_{12 \mu m}+a_{4} \cdot \text { WSA } \\
D L S T=a_{0}+a_{1} \cdot N D V I+a_{2} \cdot \text { Altitude }+a_{3} \cdot \varepsilon_{12 \mu m}+a_{4} \cdot \text { WSA }+a_{5} \cdot \text { MAST }+a_{6} \cdot \text { YAST }+a_{7} \cdot \text { Theta }
\end{gathered}
$$

The validity of the scale invariance assumption is evidenced in Figure 5 where the relationship between the employed (Table 2) $1 \mathrm{~km}$ MODIS and $4 \mathrm{~km}$ SEVIRI mean LST data and LST predictors is presented both for daytime (10:30 UTC) and nighttime (22:30 UTC). In detail, the corresponding $1 \mathrm{~km}$ and $4 \mathrm{~km}$ point clouds of Figure 5 coincide and have similar shapes and comparable Rho values. Hence, it is assumed that the LST data-predictor relation is consistent for the $1 \mathrm{~km}$ and $4 \mathrm{~km}$ spatial scales and thus the use of Equations (5) and (6) for downscaling the SEVIRI data is possible.
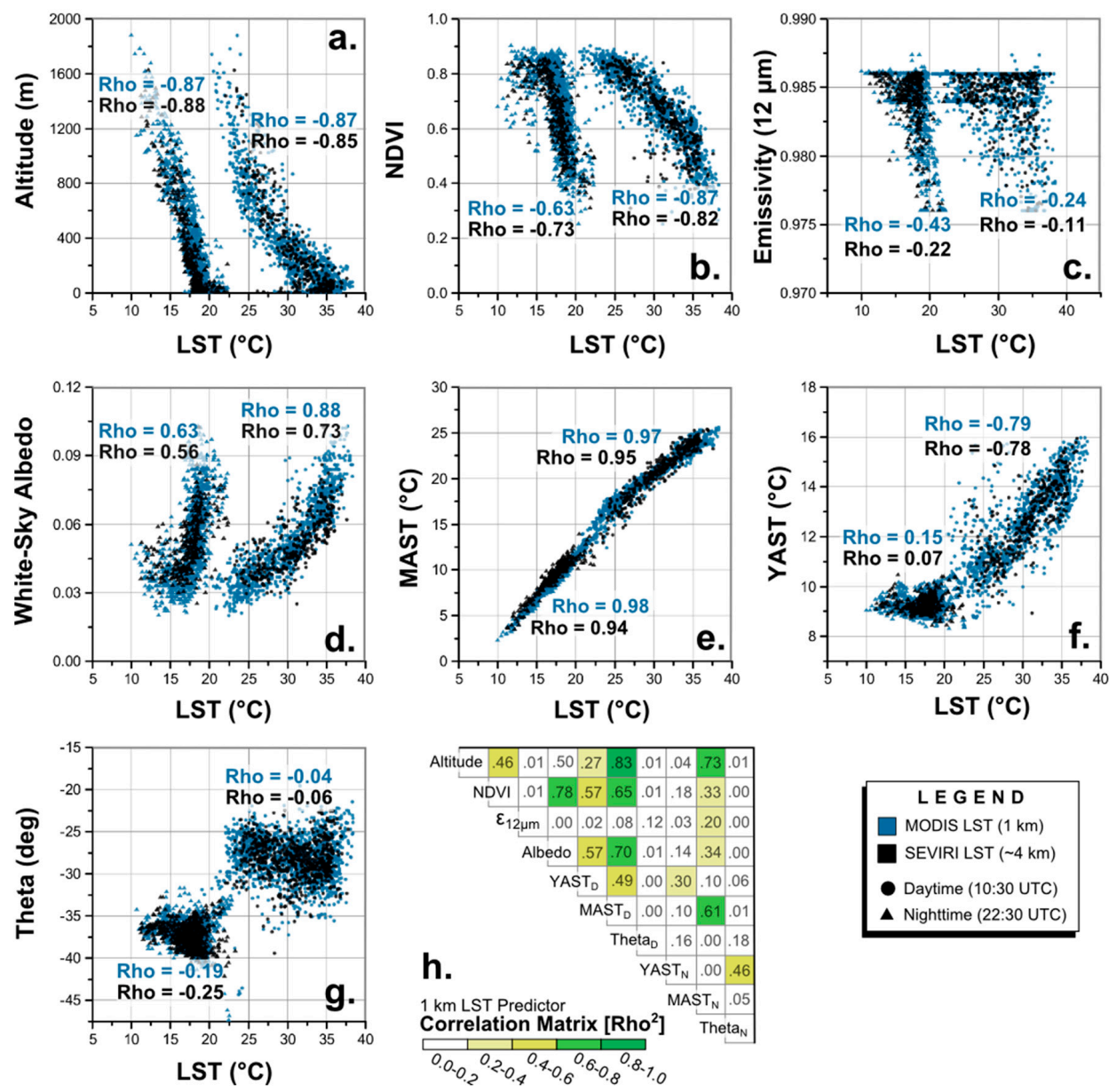

Figure 5. The relationship between the utilized LST predictors ((a) Altitude; (b) NDVI; (c) $\varepsilon_{12 \mu m}$; (d) WSA; (e) YAST; (f) MAST; and (g) Theta) and the employed mean $1 \mathrm{~km}$ MODIS and $4 \mathrm{~km}$ SEVIRI daytime (10:30 UTC) and nighttime (22:30 UTC) LST data; and (h) the correlation matrix of the employed $1 \mathrm{~km}$ LST predictors. 
The moderate-to-high Rho values of Figure 5 (with the exception of Theta, $\varepsilon_{12 \mu \mathrm{m}}$, and nighttime YAST) also suggest that the employed LST predictors provide relevant information to the downscaling process and thus meet the connectivity assumption [11]. Specifically, the highest Rho values correspond to MAST, altitude, WSA and NDVI LST predictors and the lowest to Theta. A change in Rho between daytime and nighttime is also observable, especially for YAST, WSA and NDVI. Finally, the dependency of the employed LST predictors is presented in the correlation matrix of Figure 5. In Figure 5, it is evident that the dependency between the utilized LST predictors is in most cases low. Nonetheless, a moderate dependency between altitude and NDVI, and YAST (10:30 UTC) and NDVI and WSA is evident, as well as a high association between MAST (10:30 UTC and 22:30 UTC) and Altitude.

\section{Results}

\subsection{Statistical Comparison of the Downscaled Data with the Reference Data}

Overall, the inclusion of MAST, YAST and Theta as LST predictors improved considerably the estimation of the diurnal range from the DLST data (Figure 6). In particular, for the 10:30 vs. 22:30 UTC analysis the RMSE is reduced from $1.4^{\circ} \mathrm{C}$ for Scheme 1 to $1.0^{\circ} \mathrm{C}$ for Scheme 2, while the Mean Absolute error (MAE) from $1.1^{\circ} \mathrm{C}$ to $0.8^{\circ} \mathrm{C}$ (Table 3). The corresponding values for the 13:30 vs. 01:30 UTC analysis are RMSE $2.0^{\circ} \mathrm{C}$ and $1.6^{\circ} \mathrm{C}$, respectively, and MAE $1.6^{\circ} \mathrm{C}$ and $1.2^{\circ} \mathrm{C}$. The mean difference (bias) with the reference MODIS data in all cases is close to $0{ }^{\circ} \mathrm{C}$.
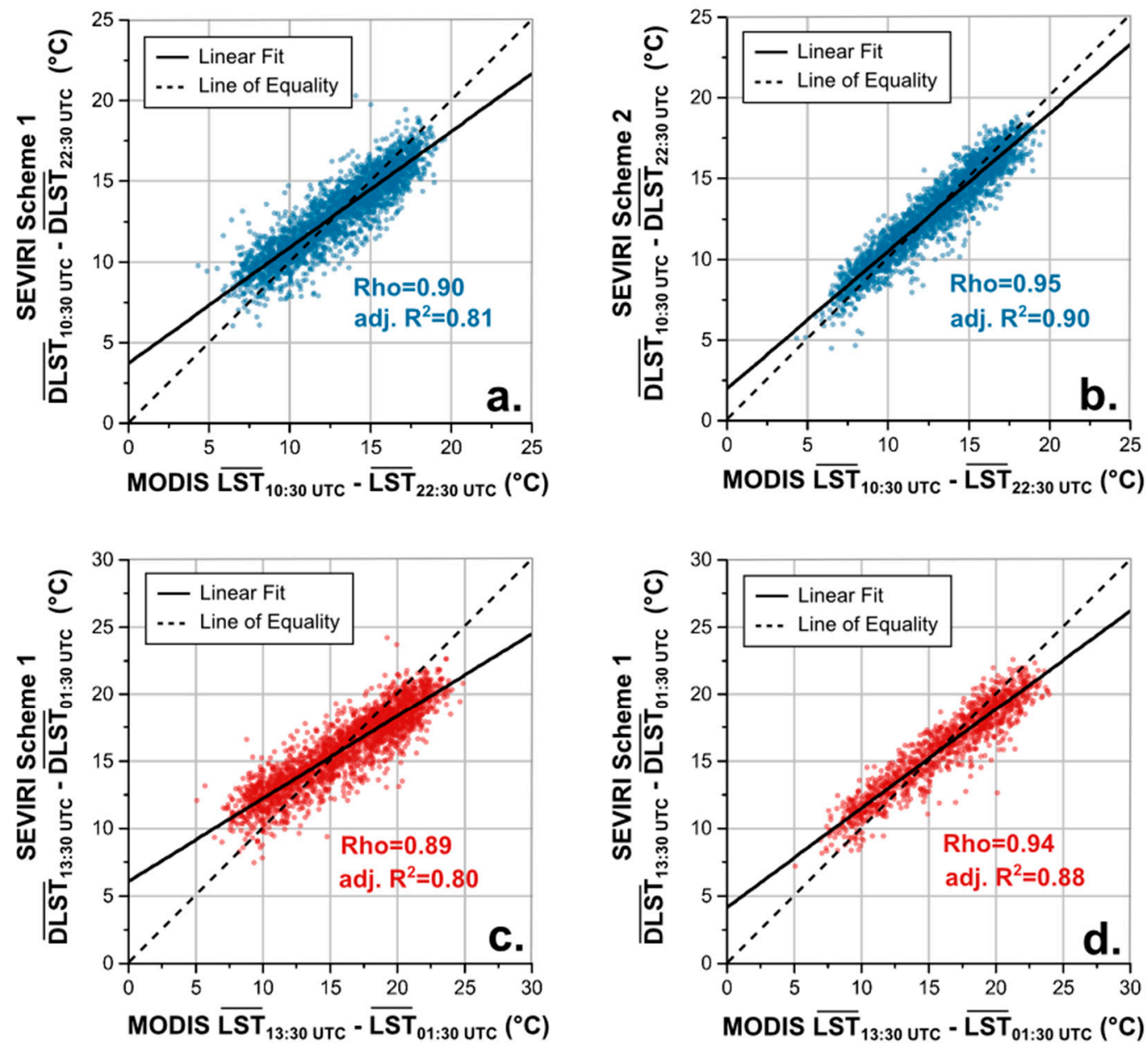

Figure 6. Scatterplots of the mean diurnal DLST range (daytime minus nighttime) versus the reference data for the 10:30 vs. 22:30 UTC analysis ((a) Scheme 1; and (b) Scheme 2 data) and the 13:30 vs. 01:30 UTC analysis ((c) Scheme 1; and (d) Scheme 2 data). 
Table 3. Various statistical measures quantifying the difference of the DLST diurnal range data with the reference MODIS data.

\begin{tabular}{|c|c|c|c|c|}
\hline \multirow{2}{*}{ Statistical Measure } & \multicolumn{2}{|c|}{ 10:30 vs. $22: 30$ UTC Analysis } & \multicolumn{2}{|c|}{ 13:30 vs. 01:30 UTC Analysis } \\
\hline & Scheme 1 & Scheme 2 & Scheme 1 & Scheme 2 \\
\hline Mean Difference (Bias) & $-0.1^{\circ} \mathrm{C}$ & $-0.1^{\circ} \mathrm{C}$ & $+0.2{ }^{\circ} \mathrm{C}$ & $+0.1^{\circ} \mathrm{C}$ \\
\hline MAE & $1.1^{\circ} \mathrm{C}$ & $0.8^{\circ} \mathrm{C}$ & $1.6^{\circ} \mathrm{C}$ & $1.2^{\circ} \mathrm{C}$ \\
\hline RMSE & $1.4^{\circ} \mathrm{C}$ & $1.0^{\circ} \mathrm{C}$ & $2.0^{\circ} \mathrm{C}$ & $1.6^{\circ} \mathrm{C}$ \\
\hline Rho & 0.90 & 0.95 & 0.89 & 0.94 \\
\hline
\end{tabular}

The similarity of the DLST diurnal range data with the reference data is also increased with the use of the ACPs as LST predictors. Specifically, Rho increased from 0.90 to 0.95 for the 10:30 vs. 22:30 UTC analysis and from 0.89 to 0.94 for the 13:30 vs. 01:30 UTC analysis (Table 3). This is also evident in the scatterplots of Figure 6, where the point clouds of Scheme 2 match better the line of equality $(y=x)$ than those of Scheme 1 . Specifically for the 10:30 vs. 22:30 UTC analysis, the intercept of Scheme 1's linear fit is 3.72 and the slope 0.72 , while for Scheme 2 the corresponding values are 1.97 and 0.85 , respectively. For the 13:30 vs. 01:30 UTC analysis, the intercept and slope are 6.07 and 0.61 for Scheme 1, and 4.15 and 0.73 for Scheme 2, respectively.

The use of MAST, YAST and Theta also improved the distribution of the DLST diurnal range as Figure 7 and Table 4 reveal. In detail the distributions of Scheme 2 data are more widespread and match better the reference data in contrast to Scheme 1, which is more condensed over the middle-range values (i.e., the 25 th-75th percentiles). Nevertheless, the mean and median values of both Scheme 1 and Scheme 2 are almost the same and equal to the reference MODIS data $\left(\sim 13^{\circ} \mathrm{C}\right.$ for the $10: 30 \mathrm{vs}$. 22:30 UTC analysis and $\sim 16^{\circ} \mathrm{C}$ for the $13: 30$ vs. 01:30 UTC analysis; Table 4).

The inclusion of the ACPs also improved the estimation of the minimum DLST diurnal range and the $1 \%$ and $5 \%$ percentiles (Table 4 ). In particular, for the 10:30 vs. 22:30 UTC analysis, the minimum dropped from $5.7^{\circ} \mathrm{C}$ for Scheme 1 to $3.3^{\circ} \mathrm{C}$ for Scheme 2 (the reference is $1.1^{\circ} \mathrm{C}$ ). A similar but not so pronounced improvement is also observable for the $13: 30$ vs. 01:30 UTC analysis (from $7.2{ }^{\circ} \mathrm{C}$ to $6.6^{\circ} \mathrm{C}$; Ref. $=1.8^{\circ} \mathrm{C}$ ). However, the inclusion of the ACPs as LST predictors did not improve the estimation of the $95 \%, 99 \%$ and maximum DLST diurnal range, which deviates for about $1-2{ }^{\circ} \mathrm{C}$ from the reference data for both schemes.
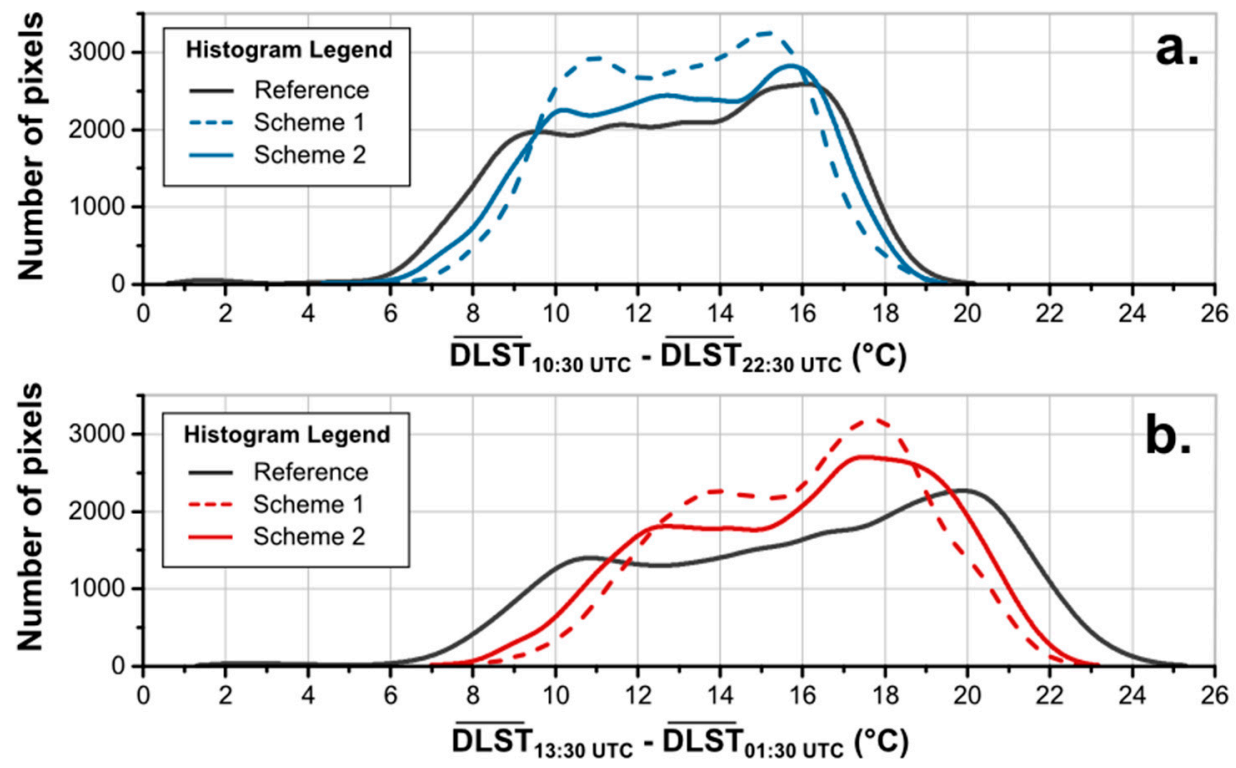

Figure 7. Histograms presenting the distribution of: (a) the DLST $10: 30$ UTC minus DLST $22: 30$ UTC; and (b) DLST $_{13: 30}$ UTC minus DLST $01: 30$ UTC data in respect to the reference MODIS data. 
Table 4. The mean, minimum, maximum and $1 \%, 5 \%, 25 \%, 50 \%$ (median), $75 \%$, $95 \%$ and $99 \%$ values of the reference LST and Scheme 1 and Scheme 2 DLST diurnal range data.

\begin{tabular}{|c|c|c|c|c|c|c|c|c|c|c|c|}
\hline \multirow{2}{*}{ Analysis } & \multirow{2}{*}{ Data } & \multirow{2}{*}{$\begin{array}{c}\text { Mean } \\
\left({ }^{\circ} \mathrm{C}\right)\end{array}$} & \multirow{2}{*}{$\begin{array}{l}\text { Min. } \\
\left({ }^{\circ} \mathrm{C}\right)\end{array}$} & \multirow{2}{*}{$\begin{array}{l}\text { Max. } \\
\left({ }^{\circ} \mathrm{C}\right)\end{array}$} & \multicolumn{7}{|c|}{ Percentiles $\left({ }^{\circ} \mathrm{C}\right)$} \\
\hline & & & & & $1 \%$ & $5 \%$ & $25 \%$ & $50 \%$ & $75 \%$ & $95 \%$ & $99 \%$ \\
\hline \multirow{3}{*}{$\begin{array}{l}\text { 10:30 vs. } \\
\text { 22:30 UTC }\end{array}$} & Reference & 12.9 & 1.1 & 20.1 & 6.3 & 7.7 & 10.3 & 13.1 & 15.6 & 17.4 & 18.3 \\
\hline & Scheme 1 & 13.0 & 5.7 & 21.3 & 7.9 & 9.1 & 11.0 & 13.1 & 15.1 & 16.8 & 17.9 \\
\hline & Scheme 2 & 13.0 & 3.3 & 19.3 & 7.1 & 8.5 & 10.9 & 13.1 & 15.4 & 17.1 & 18.0 \\
\hline \multirow{3}{*}{$\begin{array}{l}\text { 13:30 vs. } \\
\text { 01:30 UTC }\end{array}$} & Reference & 16.0 & 1.8 & 25.7 & 7.4 & 9.2 & 12.7 & 16.6 & 19.5 & 21.8 & 23.1 \\
\hline & Scheme 1 & 15.9 & 7.2 & 25.2 & 9.6 & 11.3 & 13.8 & 16.3 & 18.1 & 20.2 & 21.2 \\
\hline & Scheme 2 & 16.0 & 6.6 & 22.9 & 9.1 & 10.7 & 13.4 & 16.5 & 18.6 & 20.6 & 21.5 \\
\hline
\end{tabular}

\subsection{Analysis of the Spatial Patterns and the Impact of Land Cover and Altitude}

For Rome Greater Region, the most pronounced diurnal DLST range corresponds to the rural area surrounding the City of Rome (Figures 8 and 9). Specifically, the mean rural 10:30 vs. 22:30 UTC DLST diurnal range is $15.9^{\circ} \mathrm{C}$ for Scheme 1 and $16.3^{\circ} \mathrm{C}$ for Scheme 2 (Ref. $=16.6^{\circ} \mathrm{C}$ ), while the corresponding 13:00 vs. 01:30 UTC values are $18.6^{\circ} \mathrm{C}$ and $19.1{ }^{\circ} \mathrm{C}$, respectively (Ref. $=20.5^{\circ} \mathrm{C}$ ). In both cases, Scheme 2 is closer to the reference data than Scheme 1 (Figure 8). The weakest DLST diurnal range corresponds to the Apennine Mountains. In particular, the reference mean diurnal range for the Apennines is $10.4{ }^{\circ} \mathrm{C}$ for the 10:30 vs. $22: 30 \mathrm{UTC}$ analysis and $12.4^{\circ} \mathrm{C}$ for the $13: 00 \mathrm{vs}$. 01:30 UTC analysis. Both Scheme 1 and Scheme 2 overestimate these values by $\sim 1^{\circ} \mathrm{C}$ (Figure 8).

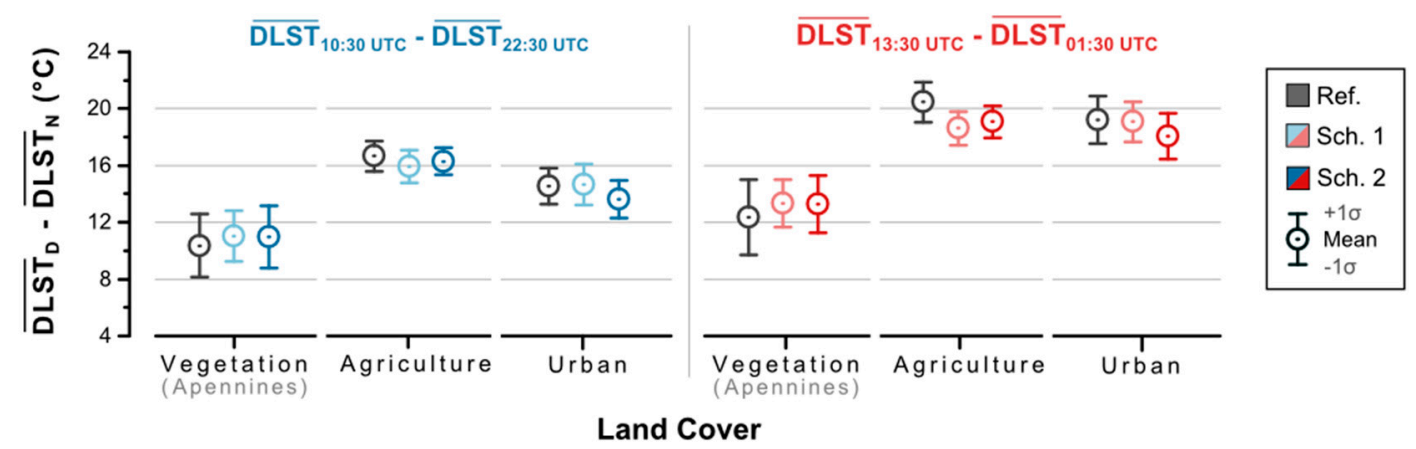

Figure 8. The mean DLST diurnal range (and standard deviation) for areas covered by vegetation (over the Apennines), agriculture and urban land cover classes.

For the City of Rome, the 10:30 vs. 22:30 UTC DLST diurnal range is $14.7^{\circ} \mathrm{C}$ for Scheme 1 and $13.6^{\circ} \mathrm{C}$ for Scheme 2 (Ref. $=14.5^{\circ} \mathrm{C}$ ). The corresponding values for the 13:30 vs. 01:30 UTC analysis are $19.1^{\circ} \mathrm{C}$ and $18.1^{\circ} \mathrm{C}$, respectively (Ref. $=19.2^{\circ} \mathrm{C}$ ). In both cases Scheme 1 performed slightly better than Scheme 2, which underestimated the reference mean by $1{ }^{\circ} \mathrm{C}$. Nevertheless, the shape of the spatial pattern of Rome's built-up is more similar to the reference data in Scheme 2 than of Scheme 1 (Figure 9). In detail, the thermal spatial pattern of Rome's urban agglomeration exhibits a very distinct thermal behavior due to the Surface Urban Heat Island (SUHI) effect. This effect is primarily caused by the higher thermal conductivity and heat storage capacity of impervious surfaces (e.g., concrete and asphalt) $[4,34]$ and results to increased urban nighttime temperatures. In this study, this effect is evidenced as a weakening of the DLST diurnal range of Rome and the formation of a very distinct spatial feature that looks like a hole (Figure 9). In particular, Rome's 10:30 vs. 22:30 UTC diurnal range pattern is presented for Schemes 1 and 2 in Figure 9h,i, respectively. The comparison with the reference data (Figure 9g) reveals that Scheme 2 outperformed Scheme 1, which underestimated the 10:30 vs. 22:30 UTC DLST change of the city's eastern part. 

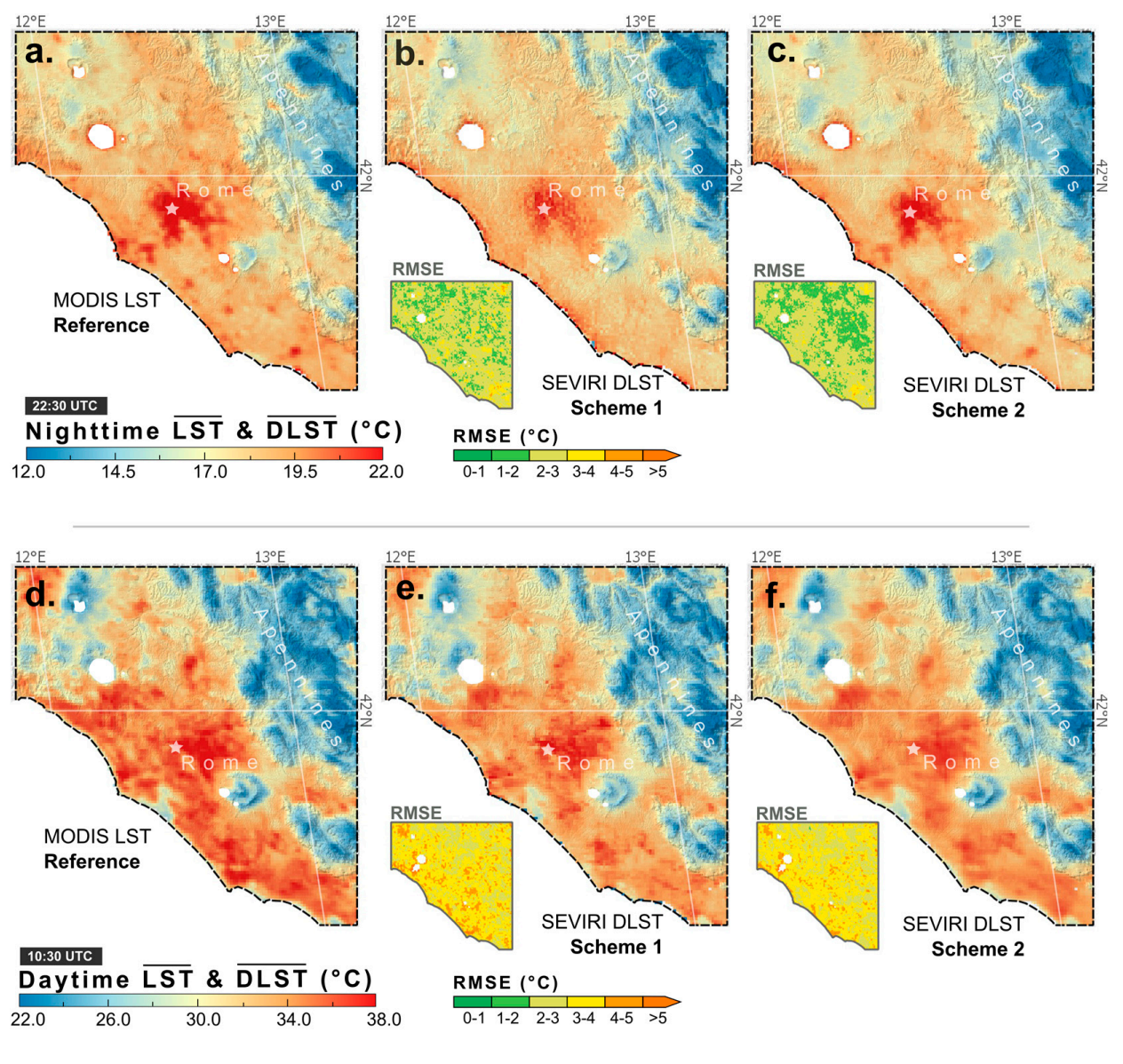

Scheme 2

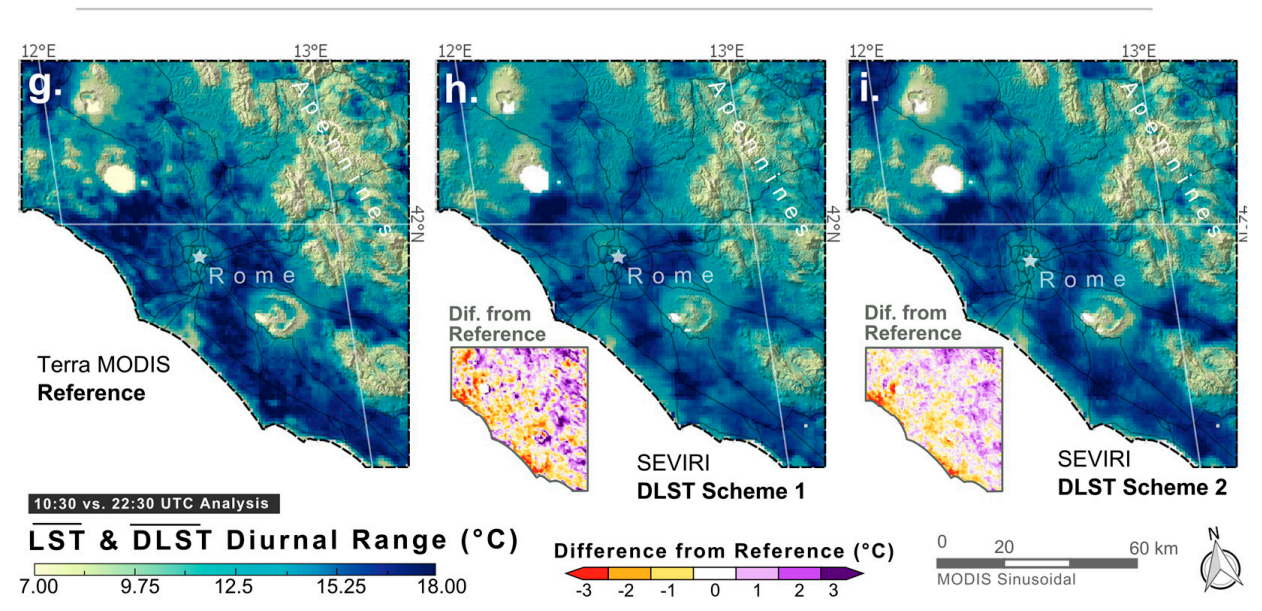

Figure 9. The 22:30 UTC (a-c) and 10:30 UTC (d-f) mean LST and DLST maps and the corresponding diurnal range maps (g-i) for: MODIS LST; SEVIRI DLST Scheme 1; and SEVIRI DLST Scheme 2.

The better performance of Scheme 2 in respect to Scheme 1 in reproducing the reference LST diurnal range spatial patterns is also observable in the "Difference from Reference" maps of Figure 9. Overall, both Scheme 1 and Scheme 2 show the same spatial features: an overestimation (purple colors) over the Apennines and an underestimation (orange colors) over the rural area surrounding the City of Rome. However, the magnitude of the differences from the reference data is considerably greater for Scheme 1 than for Scheme 2 (the above also applies for the 13:30 vs. 01:30 UTC analysis). The exception is the coastline where both Scheme 1 and Scheme 2 underestimated its diurnal DLST range. This problem is mainly due to two reasons: (i) the LST retrieval of coastline pixels which 
is known to be more error prone due to emissivity uncertainties [1]; and (ii) the difference in pixel size between SEVIRI and MODIS, which can result in considerably different samplings over highly heterogeneous regions (e.g., coastlines) [50].

The assessment of the obtained DLST diurnal range data concludes with an analysis of how they change with altitude. In Figure 10, the relationship between the mean DLST diurnal range and altitude is presented. Overall, the curves of Scheme 1 and Scheme 2 match well with the curve of the reference MODIS data. As expected, a slight overestimation of the DLST diurnal range for the areas with an altitude greater that $500 \mathrm{~m}$ is evident for both schemes. For the 50-500 m range, the results are substantially better and the DLST data almost match the reference data.
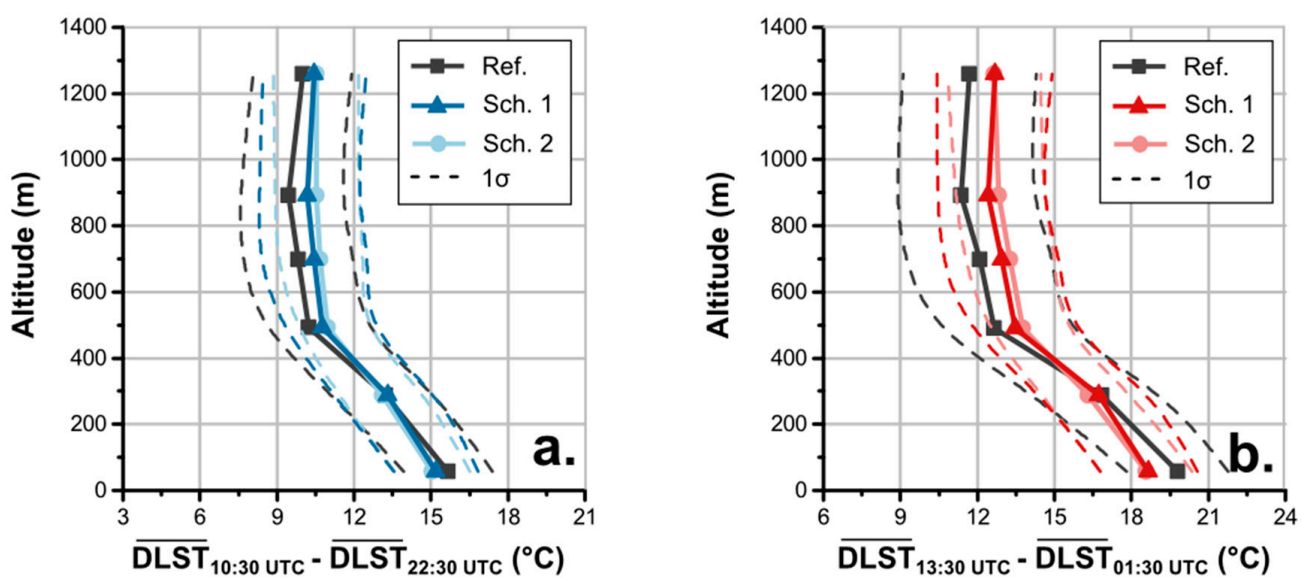

Figure 10. The mean DLST diurnal range in respect to altitude: (a) for the 10:30 vs. 22:30 UTC analysis; and (b) for the 13:30 vs. 01:30 UTC analysis.

\subsection{Similarity of the Employed MODIS LST and SEVIRI DLST Time Series}

Finally, a comparison between the daytime and nighttime MODIS LST (Table 2) and the corresponding SEVIRI DLST datasets is given. Overall the employed data exhibit a high degree of similarity, with Scheme 2 data to perform slighty better than Scheme 1 (Table 5). The mean difference between the $1 \mathrm{~km}$ SEVIRI DLST and MODIS LST data ranges from 0 to $-0.5^{\circ} \mathrm{C}$ while RMSE is close to $\sim 1.3^{\circ} \mathrm{C}$ for the nighttime data and $\sim 2.5^{\circ} \mathrm{C}$ for the daytime data. The standard deviation of the MODIS LST-SEVIRI DLST differences is $\sim 2.5^{\circ} \mathrm{C}$ for the 10:30 UTC and 13:30 UTC data and $\sim 1.2{ }^{\circ} \mathrm{C}$ for the 01:30 UTC and 22:30 UTC data. Rho is equal to $\sim 0.9$ for all cases. Scheme 2 outperforms Scheme 1 at all acquisitions times but the added value is highest at 01:30 and 10:30 UTC while it is rather little at 13:30 UTC.

Table 5. The differences between the employed MODIS LST and SEVIRI DLST Scheme 1 (Sch. 1) and Scheme 2 (Sch. 2) data.

\begin{tabular}{|c|c|c|c|c|c|c|c|c|}
\hline \multirow{2}{*}{ Statistical Measures } & \multicolumn{2}{|c|}{ 01:30 UTC } & \multicolumn{2}{|c|}{ 10:30 UTC } & \multicolumn{2}{|c|}{ 13:30 UTC } & \multicolumn{2}{|c|}{$22: 30$ UTC } \\
\hline & Sch. 1 & Sch. 2 & Sch. 1 & Sch. 2 & Sch. 1 & Sch. 2 & Sch. 1 & Sch. 2 \\
\hline Mean Difference (Bias) $\left({ }^{\circ} \mathrm{C}\right)$ & -0.41 & -0.41 & -0.46 & -0.46 & -0.19 & -0.16 & -0.48 & -0.50 \\
\hline Standard Deviation $\left({ }^{\circ} \mathrm{C}\right)$ & 1.37 & 1.00 & 2.44 & 2.29 & 2.70 & 2.64 & 1.31 & 1.14 \\
\hline $\operatorname{RMSE}\left({ }^{\circ} \mathrm{C}\right)$ & 1.43 & 1.08 & 2.48 & 2.33 & 2.70 & 2.65 & 1.40 & 1.23 \\
\hline Rho & 0.87 & 0.93 & 0.87 & 0.89 & 0.87 & 0.88 & 0.89 & 0.91 \\
\hline
\end{tabular}

The high similarity of the mean SEVIRI DLST with the MODIS LST data is also evident in Figure 9a-f. Overall the same spatial features are presented in the corresponding maps. The most pronounced spatial pattern difference is the nighttime DLST pattern of Rome of Scheme 1, which is due to the weakening of the relationship between the LST predictors and the nighttime LST data. 


\section{Discussion}

The results of this study suggest that the use of MAST, YAST and Theta as LST predictors improve the downscaling of coarse-scale LST data and the estimation of the diurnal range from the DLST data. MAST, YAST and Theta represent the thermal landscape of a region $[28,29]$ and can be estimated for various times within a day (e.g., morning, noon, afternoon and night) depending on the overpass time of the satellite. Hence, these LST predictors can be very useful for the downscaling of geostationary diurnal LST data, which is a more demanding process than the downscaling of single scenes. This is because the spatiotemporal interrelationships of the LST data, which are driven by the thermodynamic characteristics of the surface materials the short-term meteorological conditions and the diurnal and annual cycle of heating and cooling, have to be preserved [15].

In this work MAST, YAST and Theta improved the downscaling of both daytime and nighttime LST data as well as their interrelationship. The former is evident through the comparison with the corresponding MODIS data and the latter with the estimation of the DLST diurnal range, which is the main focus of this paper. The estimation of diurnal thermal differences, (e.g., daytime minus nighttime), is particularly useful for numerous studies such as: the assessment of regional and global climate change [51,52]; the estimation of evapotranspiration $[3,27,53]$; the assessment and monitoring of the SUHI effect $[19,21,54]$; the estimation of crop yield [55]; and the assessment of excess heat effects to human health [56] (for most of these studies a LST accuracy of $1{ }^{\circ} \mathrm{C}$ or better is required [1]). The use of the three ACP components as LST predictors improved considerably the thermal spatial patterns of the nighttime data, which were influenced by the weakening of the LST predictors' relationship with LST [24]. In addition, MAST, YAST and Theta improved the estimation of the very low DLST values and the overall distribution of the DLST diurnal range. Usually downscaling schemes tend to be biased in the extreme LST ranges [20], due to the small number of extreme LST pixels and the presence of outliers [10].

The inconsistency in the performance of LST predictors, both in respect to time and location, is another important issue in the downscaling literature [41,57]. This is because it complicates or even prohibits the transfer of a downscaling scheme designed for a specific area to another area with different landscape and climatic characteristics [15,57]. For instance, NDVI-based downscaling schemes do not perform well over complex heterogeneous regions [57] and for this reason alternative approaches have been proposed (e.g., [20]). Such inconsistencies are also evident when working with different land cover types. This is because the explanatory power of an LST predictor varies in respect to land cover. For instance, the impervious surface cover is more appropriate for downscaling urban areas than NDVI [26] and vice versa. To that end, MAST, YAST and Theta offer the advantage of a stable performance over various land cover types, landscapes and climatic conditions. This is because, being derived from LST data, they incorporate the location-specific variability, e.g., the effects of topographic shading [28], and how this variability changes with time (when multitemporal MAST, YAST and Theta data are being used). This fact makes them especially useful for downscaling geostationary diurnal LST data. In addition, it also implies that the inclusion of YAST, MAST and Theta can help limit the size of the LST predictor set, which is more practical and performs better as some studies $[7,41]$ suggest. However, the good performance of the ACPs depends on the multi-year time series of satellite LST data used for their estimation. Specifically, the employed time series should deliver a sufficient sample size that is not affected by short weather effects and does not cover substantial changes in the climatic or surface conditions (e.g., a burnt scar) in order to be accurate $[28,29]$. Otherwise, artifacts may occur [28].

Another important issue that may prohibit the use of a dataset as LST predictors is the scale invariance assumption, i.e., the relationship between the LST data and LST predictors to be the same between the coarse and fine spatial scale $[7,15,23]$. For NDVI it is known that as the spatial scale becomes finer the near-linear relationship with coarse-scale LST transforms to a trapezoid and weakens [23]. In this work, the scale invariance assumption for MAST, YAST and Theta was validated for the $4 \mathrm{~km}$ and $1 \mathrm{~km}$ spatial scales. Strong evidence that support the validity of the scale invariance 
assumption for MAST, YAST and Theta for finer scale resolutions are available in [7], where the ACPs were used in conjunction with other LST predictors to downscale a SEVIRI scene down to $100 \mathrm{~m}$ $\left(\mathrm{RMSE}=2.2^{\circ} \mathrm{C}\right)$. However, more detailed tests are still required.

\section{Conclusions}

This study discusses the downscaling of geostationary diurnal LST data with the use of multitemporal LST predictors and assesses if MAST, YAST and Theta can improve the downscaling performance. The rationale behind this work is that multitemporal MAST, YAST and Theta can provide information about the spatial distribution of the LST for different times of a day and thus improve the estimation of DLST and DLST diurnal changes, both in terms of magnitude and pattern shape. The results of this study support the aforementioned hypothesis. The SEVIRI ACP-based DLST data showed a better similarity and lower RMSE and MAE values with the reference MODIS data in comparison to DLST data estimated using a set of VNIR-based and static LST predictors. In addition, the findings of this work suggest that the ACPs improved the DLST spatial patterns-especially for the nighttime data-and the distribution of the DLST diurnal range values. Overall, the use of MAST, YAST and Theta as LST predictors offers many advantages to the downscaling process and can prove an important step towards the maturing of this technology. This is important because a LST downscaling is currently the main way to obtain LST data that match the characteristic scale of the LST diurnal cycle.

Acknowledgments: EUMETSAT is the source of the original Meteosat Images. The SEVIRI data were acquired by the EUMETCast station operated by the Institute for Astronomy, Astrophysics, Space Application and Remote Sensing of the National Observatory of Athens. The MODIS data products were obtained from NASA's Earth Observing System Data and Information System (EOSDIS). This publication was supported: (i) by the Excellence Research Programme GSRT (2015-2017) ARISTOTELIS “Environment, Space and Geodynamics/Seismology 2015-2017"; (ii) by the Cluster of Excellence CliSAP (EXC 177), University of Hamburg funded through the German Science Foundation (DFG); and (iii) by an A.G. Leventis Foundation scholarship.

Author Contributions: Panagiotis Sismanidis conceived, designed and performed the experiment and wrote the paper. Iphigenia Keramitsoglou and Chris T. Kiranoudis monitored the experimental process and produced the SEVIRI LST data. Benjamin Bechtel significantly contributed to the conceptual framework of this study and produced the ACP data. All authors reviewed the manuscript.

Conflicts of Interest: The authors declare no conflict of interest.

\section{Abbreviations}

The following abbreviations are used in this manuscript:

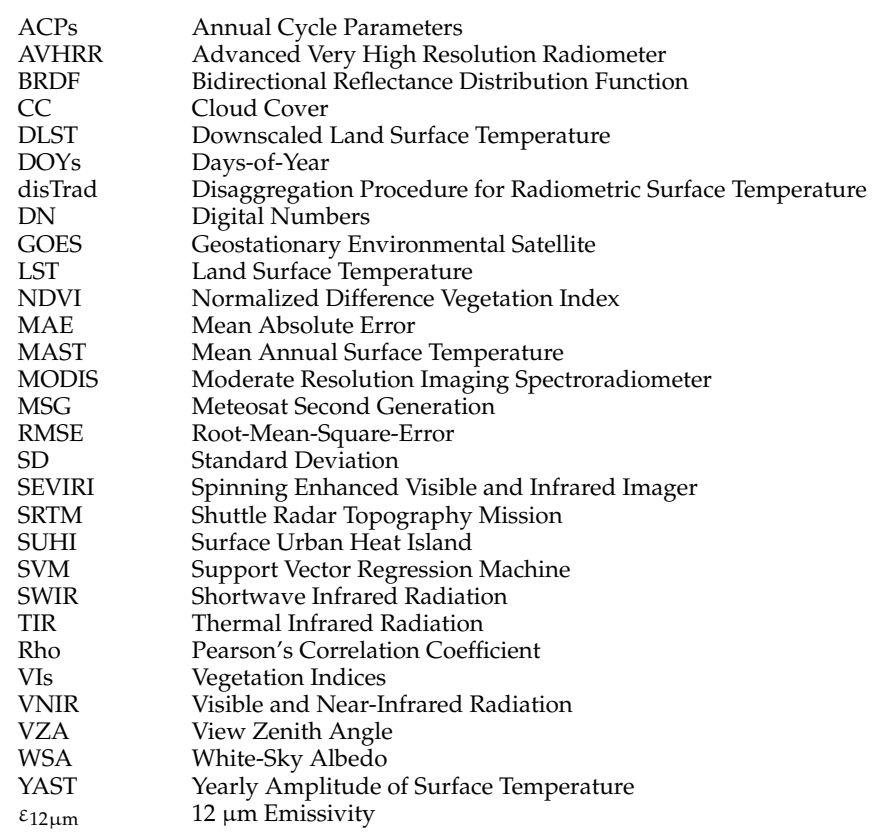




\section{References}

1. Li, Z.-L.; Tang, B.-H.; Wu, H.; Ren, H.; Yan, G.; Wan, Z.; Trigo, I.F.; Sobrino, J.A. Satellite-derived land surface temperature: Current status and perspectives. Remote Sens. Environ. 2013, 131, 14-37. [CrossRef]

2. Norman, J.M.; Becker, F. Terminology in thermal infrared remote sensing of natural surfaces. Agric. For. Meteorol. 1995, 77, 153-166. [CrossRef]

3. Kalma, J.D.; McVicar, T.R.; McCabe, M.F. Estimating land surface evaporation: A review of methods using remotely sensed surface temperature data. Surv. Geophys. 2008, 29, 421-469. [CrossRef]

4. Voogt, J.A.; Oke, T. Thermal remote sensing of urban climates. Remote Sens. Environ. 2003, 86, 370-384. [CrossRef]

5. Krishnan, P.; Kochendorfer, J.; Dumas, E.J.; Guillevic, P.C.; Bruce Baker, C.; Meyers, T.P.; Martos, B. Comparison of in-Situ, aircraft, and satellite land surface temperature measurements over a NOAA climate reference network site. Remote Sens. Environ. 2015, 165, 249-264. [CrossRef]

6. Quattrochi, D.A.; Goel, N.S. Spatial and temporal scaling of thermal infrared remote sensing data. Remote Sens. Rev. 1995, 12, 255-286. [CrossRef]

7. Bechtel, B.; Zakšek, K.; Hoshyaripour, G. Downscaling land surface temperature in an urban area: A case study for Hamburg, Germany. Remote Sens. 2012, 4, 3184-3200. [CrossRef]

8. Stathopoulou, M.; Cartalis, C. Downscaling AVHRR land surface temperatures for improved surface urban heat island intensity estimation. Remote Sens. Environ. 2009, 113, 2592-2605. [CrossRef]

9. Kustas, W.P.; Norman, J.M.; Anderson, M.C.; French, A.N. Estimating subpixel surface temperatures and energy fluxes from the vegetation index-radiometric temperature relationship. Remote Sens. Environ. 2003, 85, 429-440. [CrossRef]

10. Agam, N.; Kustas, W.P.; Anderson, M.C.; Li, F.; Neale, C.M.U. A vegetation index based technique for spatial sharpening of thermal imagery. Remote Sens. Environ. 2007, 107, 545-558. [CrossRef]

11. Zhan, W.; Chen, Y.; Zhou, J.; Wang, J.; Liu, W.; Voogt, J.; Zhu, X.; Quan, J.; Li, J. Disaggregation of remotely sensed land surface temperature: Literature survey, taxonomy, issues, and caveats. Remote Sens. Environ. 2013, 131, 119-139. [CrossRef]

12. Zhan, W.; Chen, Y.; Zhou, J.; Li, J.; Liu, W. Sharpening thermal imageries: A generalized theoretical framework from an assimilation perspective. IEEE Trans. Geosci. Remote Sens. 2011, 49, 773-789. [CrossRef]

13. Chen, Y.; Zhan, W.; Quan, J.; Zhou, J.; Zhu, X.; Sun, H. Disaggregation of Remotely sensed land surface temperature: A generalized paradigm. IEEE Trans. Geosci. Remote Sens. 2014, 52, 5952-5965. [CrossRef]

14. Tobler, W.R. A computer movie simulating urban growth in the Detroit region. Econ. Geogr. 1970, 46, $234-240$. [CrossRef]

15. Sismanidis, P.; Keramitsoglou, I.; Kiranoudis, C.T.; Bechtel, B. Assessing the capability of a downscaled urban land surface temperature time series to reproduce the spatiotemporal features of the original data. Remote Sens. 2016, 8. [CrossRef]

16. Inamdar, A.K.; French, A. Disaggregation of GOES land surface temperatures using surface emissivity. Geophys. Res. Lett. 2009, 36, 1-5. [CrossRef]

17. Inamdar, A.K.; French, A.; Hook, S.; Vaughan, G.; Luckett, W. Land surface temperature retrieval at high spatial and temporal resolutions over the southwestern United States. J. Geophys. Res. 2008, 113, 1-18. [CrossRef]

18. Weng, Q.; Fu, P. Modeling diurnal land temperature cycles over Los Angeles using downscaled GOES imagery. ISPRS J. Photogramm. Remote Sens. 2014, 97, 78-88. [CrossRef]

19. Keramitsoglou, I.; Kiranoudis, C.T.; Weng, Q. Downscaling geostationary land surface temperature imagery for urban analysis. IEEE Geosci. Remote Sens. Lett. 2013, 10, 1253-1257. [CrossRef]

20. Hutengs, C.; Vohland, M. Downscaling land surface temperatures at regional scales with random forest regression. Remote Sens. Environ. 2016, 178, 127-141. [CrossRef]

21. Zakšek, K.; Oštir, K. Downscaling land surface temperature for urban heat island diurnal cycle analysis. Remote Sens. Environ. 2012, 117, 114-124. [CrossRef]

22. Duan, S.; Li, Z. Spatial downscaling of MODIS land surface temperatures using geographically weighted regression: Case study in northern China. IEEE Trans. Geosci. Remote Sens. 2016, 54, 6458-6469. [CrossRef] 
23. Jeganathan, C.; Hamm, N.A.S.; Mukherjee, S.; Atkinson, P.M.; Raju, P.L.N.; Dadhwal, V.K. Evaluating a thermal image sharpening model over a mixed agricultural landscape in India. Int. J. Appl. Earth Obs. Geoinf. 2011, 13, 178-191. [CrossRef]

24. Sun, D.; Kafatos, M. Note on the NDVI-LST relationship and the use of temperature-related drought indices over North America. Geophys. Res. Lett. 2007, 34, 1-4. [CrossRef]

25. Yuan, F.; Bauer, M.E. Comparison of impervious surface area and normalized difference vegetation index as indicators of surface urban heat island effects in Landsat imagery. Remote Sens. Environ. 2007, 106, 375-386. [CrossRef]

26. Essa, W.; Verbeiren, B.; van der Kwast, J.; Van de Voorde, T.; Batelaan, O. Evaluation of the DisTrad thermal sharpening methodology for urban areas. Int. J. Appl. Earth Obs. Geoinf. 2012, 19, 163-172. [CrossRef]

27. Merlin, O.; Duchemin, B.; Hagolle, O.; Jacob, F.; Coudert, B.; Chehbouni, G.; Dedieu, G.; Garatuza, J.; Kerr, Y. Disaggregation of MODIS surface temperature over an agricultural area using a time series of formosat-2 images. Remote Sens. Environ. 2010, 114, 2500-2512. [CrossRef]

28. Bechtel, B. A new global climatology of annual land surface temperature. Remote Sens. 2015, 7, $2850-2870$. [CrossRef]

29. Bechtel, B. Robustness of annual cycle parameters to characterize the urban thermal landscapes. IEEE Geosci. Remote Sens. Lett. 2012, 9, 876-880. [CrossRef]

30. Bechtel, B.; Böhner, J.; Zakšek, K.; Wiesner, S. Downscaling of diumal land surface temperature cycles for urban heat island monitoring. In Proceedings of the Joint Urban Remote Sensing Event, Sao Paolo, Brazil, 21-23 April 2013; pp. 8-11.

31. Zhan, W.; Huang, F.; Quan, J.; Zhu, X.; Gao, L.; Zhou, J.; Ju, W. Disaggregation of remotely sensed land surface temperature: A new dynamic methodology. J. Geophys. Res. Atmos. 2016, 121, 1-17. [CrossRef]

32. Wan, Z. Collection-5 MODIS Land Surface Temperature Products Users' Guide; ICESS, University of California: Santa Barbara, CA, USA, 2006.

33. Wan, Z.; Li, Z.-L. Radiance-based validation of the V5 MODIS land-surface temperature product. Int. J. Remote Sens. 2008, 29, 5373-5395. [CrossRef]

34. Sismanidis, P.; Keramitsoglou, I.; Kiranoudis, C.T. A satellite-based system for continuous monitoring of surface urban heat islands. Urban Clim. 2015, 14, 141-153. [CrossRef]

35. Sismanidis, P.; Keramitsoglou, I.; Kiranoudis, C.T. Evaluating the operational retrieval and downscaling of urban land surface temperatures. IEEE Geosci. Remote Sens. Lett. 2015, 12, 1312-1316. [CrossRef]

36. Trigo, I.F.; Dacamara, C.C.; Viterbo, P.; Roujean, J.-L.; Olesen, F.; Barroso, C.; Camacho-de-Coca, F.; Carrer, D.; Freitas, S.C.; García-Haro, J.; et al. The satellite application facility for land surface analysis. Int. J. Remote Sens. 2011, 32, 2725-2744. [CrossRef]

37. Rabus, B.; Eineder, M.; Roth, A.; Bamler, R. The shuttle radar topography mission-A new class of digital elevation models acquired by spaceborne radar. ISPRS J. Photogramm. Remote Sens. 2003, 57, 241-262. [CrossRef]

38. Solano, R.; Didan, K.; Jacobson, A.; Huete, A. Collection-5 MODIS Vegetation Indices (MOD13) User's Guide; Vegetation Index and Phenology Lab, The University of Arizona: Tucson, AZ, USA, 2010.

39. Strahler, A.H.; Muller, J.P. Collection-5 MODIS BRDF Albedo Product (MCD43): Algorithm Theoretical Basis Document; Boston University: Boston, MA, USA, 1999.

40. Maeda, E.E. Downscaling MODIS LST in the east African mountains using elevation gradient and land-cover information. Int. J. Remote Sens. 2014, 35, 3094-3108. [CrossRef]

41. Bisquert, M.; Sánchez, J.M.; Caselles, V. Evaluation of disaggregation methods for downscaling MODIS land surface temperature to Landsat spatial resolution in Barrax test site. IEEE J. Sel. Top. Appl. Earth Obs. Remote Sens. 2016, 9, 1430-1438. [CrossRef]

42. Rodriguez, E.; Morris, C.C.; Belz, J.J. A global assessment of the SRTM performance. Photogramm. Eng. Remote Sens. 2006, 72, 249-260. [CrossRef]

43. Snyder, W.C.; Wan, Z.; Zhang, Y.; Feng, Y.-Z. Classification-based emissivity for land surface temperature measurement from space. Int. J. Remote Sens. 1998, 19, 2753-2774. [CrossRef]

44. Hulley, G.C.; Hook, S.J. Intercomparison of versions 4, 4.1 and 5 of the MODIS land surface temperature and emissivity products and validation with laboratory measurements of sand samples from the Namib Desert, Namibia. Remote Sens. Environ. 2009, 113, 1313-1318. [CrossRef] 
45. Rodriguez-Galiano, V.; Pardo-Iguzquiza, E.; Sanchez-Castillo, M.; Chica-Olmo, M.; Chica-Rivas, M. Downscaling Landsat 7 ETM+ thermal imagery using land surface temperature and NDVI images. Int. J. Appl. Earth Obs. Geoinf. 2012, 18, 515-527. [CrossRef]

46. Holderness, T.; Barr, S.; Dawson, R.; Hall, J. An evaluation of thermal earth observation for characterizing urban heatwave event dynamics using the urban heat island intensity metric. Int. J. Remote Sens. 2013, 34, 864-884. [CrossRef]

47. Vinnikov, K.Y.; Yu, Y.; Goldberg, M.D.; Tarpley, D.; Romanov, P.; Laszlo, I.; Chen, M. Angular anisotropy of satellite observations of land surface temperature. Geophys. Res. Lett. 2012, 39, 1-7. [CrossRef]

48. Hu, L.; Monaghan, A.; Voogt, J.A.; Barlage, M. A first satellite-based observational assessment of urban thermal anisotropy. Remote Sens. Environ. 2016, 181, 111-121. [CrossRef]

49. Trigo, I.F.; Monteiro, I.T.; Olesen, F.; Kabsch, E. An assessment of remotely sensed land surface temperature. J. Geophys. Res. 2008, 113, D17108. [CrossRef]

50. Mitraka, Z.; Chrysoulakis, N.; Kamarianakis, Y.; Partsinevelos, P.; Tsouchlaraki, A. Improving the estimation of urban surface emissivity based on sub-pixel classification of high resolution satellite imagery. Remote Sens. Environ. 2012, 117, 125-134. [CrossRef]

51. Kalnay, E.; Cai, M. Impact of urbanization and land-use change on climate. Nature 2003, 423, $528-531$. [CrossRef] [PubMed]

52. Braganza, K.; Karoly, D.J.; Arblaster, J.M. Diurnal temperature range as an index of global climate change during the twentieth century. Geophys. Res. Lett. 2004, 31, 2-5. [CrossRef]

53. Idso, S.B.; Schmugge, T.J.; Jackson, R.D.; Reginato, R.J. The Utility of Surface Temperature Measurements for the Remote Sensing of Surface Soil Water Status. J. Geophys. Res. 1978, 80, 3044-3049. [CrossRef]

54. Nguyen, L.; Henebry, G. Urban heat islands as viewed by microwave radiometers and thermal time indices. Remote Sens. 2016, 8, 831. [CrossRef]

55. Lobell, D.B. Changes in diurnal temperature range and national cereal yields. Agric. For. Meteorol. 2007, 145, 229-238. [CrossRef]

56. Kan, H.; London, S.J.; Chen, H.; Song, G.; Chen, G.; Jiang, L.; Zhao, N.; Zhang, Y.; Chen, B. Diurnal Temperature range and daily mortality in Shanghai, China. Environ. Res. 2007, 103, 424-431. [CrossRef] [PubMed]

57. Gao, F.; Kustas, W.P.; Anderson, M.C. A data mining approach for sharpening thermal satellite imagery over land. Remote Sens. 2012, 4, 3287-3319. [CrossRef]

(C) 2016 by the authors; licensee MDPI, Basel, Switzerland. This article is an open access article distributed under the terms and conditions of the Creative Commons Attribution (CC-BY) license (http:/ / creativecommons.org/licenses/by/4.0/). 